\title{
Cave Paintings for the Al: Art in the Age of Singularity
}

\author{
Kasperi Mäki-Reinikka \\ Aalto University \\ PL 11000, 00076 AALTO, Finland \\ kasperi.maki-reinikka@aalto.fi
}

\begin{abstract}
In this article, I discuss the possible futures of art and aesthetic experience in the age of non-human agency, machine learning and artificial intelligence. I approach my subject from the point of view of artistic research asking: how will the dawning Singularity experience art, and how could artists take this into account while making art today. First, I will give an outline of the transhuman condition and the theory of Singularity. I'll present some examples of how biological bodies are merging with technological ones. I then present some previous examples how the theme has been approached in artists previously. I move to suggesting different theoretical tools that might help us in our task and suggest ways to negotiate between living and non-living experience. I present an artistic process of Brains on Art collective and describe a Machine Spectator we are building and some future ideas for the project. Finally, I present some ontological aspects of the machine that have been highlighted during the project.
\end{abstract}

Artificial intelligence. Transhumanism. Posthumanism. Artistic research. Aesthetic experience. Machine learning.

\section{INTRODUCTION}

In this article, I discuss the possible futures of art and aesthetic experience in the age of non-human agency, machine learning and artificial intelligence. I approach my subject from the point of view of artistic research (Hannula et al. 2005) asking: how will the dawning Singularity experience art and how could artists take this into account while making art today.

The relevance of the topic has stirred from the technological advances that have narrowed the gap between organic and inorganic, biological and technological entities (Roden 2015). If we are to believe, like transhumanist writers would have it, that we are nearing the precipice where biological and technological bodies assimilate (Kurtzweil 2005), we need to discuss how the technological other exists, what are its sensory capabilities and on what grounds could it access the register of aesthetic something previously reserved only for humans.

For this article the transhuman condition and the inevitable state of Singularity (super Al) are taken on as a thought experiment, to ignite artistic research process in order to answer questions on the sensory and material nature of a machine as well as the ability (or inability) of a machine to have an aesthetic experience. Aside from transhumanist paradigm, the article explores also other theoretical tools from posthumanism and art theories that offer promise for future artistic work.

Here I am not focusing on art made by the machine but rather on art made for the machine. There are multiple examples of art made by machines, that raise interesting questions on the creative potential of new technologies (Taylor 2014). My concern however is how to negotiate the aesthetic experience in a form a machine could understand or even appreciate.

In this article I'm focusing on visual art, although a lot has been done in the fields of electronic and experimental music and sound art, as well as generative literature and poetry.

\section{BACKGROUND}

The background of the work comes from the rapid development of technological fields that are leaking into the biological realm. The technological advances in machine learning and artificial intelligence raise major cultural questions that need to be discussed not only within computer science and information technology, but also in the humanities and art. When the new technologies work us over completely (McLuhan \& Fiore 1967), we need to find ways to imagine the possible futures. 
On one hand the topic of aesthetic experience for a machine is discussed as a speculative research question (Savransky et al. 2017) and on the other as artistic experimentation rooted in practice. To present the backgrounds of the project I first go through the artistic and theoretical thinking behind it.

\subsection{Artistic practice}

In 2010 I co-founded Brains on Art collective that includes practitioners of cognitive science and bioengineering. Together we have made installations and art exhibitions since 2013. Our previous projects include works like Brain Poetry (2013), a poem generator that produces poetry out of spectator's brain waves, and Culture - Viljelmä (2016), an enlarged petri dish to which the viewers can generate virtual organisms out of their biosignals (such as heart rate and galvanic skin response) creating an independent virtual ecosystem to the dish.

In our latest solo exhibition Museum of Imaginary Science (2017), we realized working versions of imaginary machines drawn by children. After having done an exhibition for children we started to plan our next project and a question was raised: could we make art for machines?

Trying to answer the question we are currently building a Machine Spectator, that could encounter and even appreciate art. The work done in Brains on Art collective form the artistic, practise-based background of the paper.

\subsection{Transhuman condition}

Why is it important to raise questions about how machines understand (or don't understand) art? In a line of thought called transhumanism new technological advances are seen as a possibility to transcend these feeble meat sacks we call bodies. The general idea is that through the joined effort of technologies like nanotechnology, biotechnology, information technology and cognitive science, we can greatly expand our physical and mental capabilities, extend our life spans (maybe indefinitely), and upload our brains (and consciousness) to a computer or to new bodies (Kurzweil 2005).

The argument for transhumanist thought comes from the rapid development in the above-mentioned fields of study. Nanobots could transfer drugs in our veins and fight diseases and improve our cognitive capabilities, and the advanced artificial intelligence could at some point merge with our own (Kurzweil 2005).

Humans have of course always used technologies to surpass their limited capabilities, be that technology pen and paper for augmenting our memory by writing things down (Clark 2003). But new emerging beings like artificial general intelligence needs a more thorough discussion: how do these entities exist? What are their sensory possibilities to get information about the world, and what kind of ethics and aesthetics they develop? How could they better understand the need for aesthetic experiences and art?

We are nearing the precipice where the self and the technological other assimilate to form a hybrid way of existing. Close to Transhumanism, the Singularity movement perceives the dawn of the technological Singularity as an inevitable event in the immediate future. According to these theorists, Singularity - an artificial superintelligence - will trigger a runaway growth of technology (Vinge 1993).

Ray Kurzweil's Law of Accelerating Returns (inspired by the Moore's Law) describes, among other things, how the amount of intelligent systems is growing exponentially. Kurzwail - a futurist, and prophesy-maker who was hired by Google to work on projects concerning machine learning and language processing in 2012, comes to a conclusion that this will culminate in unimaginable technological progress in the 21st century, leading to the emergence of Singularity. According to him, around 2045 we will not be able to keep up with the pace of technological change unless we merge our intelligence with that of a machine (Kurzweil 2005).

The transhumanist thought has been criticized for its limited view of life and what does it mean to be human. It continues to build on the human-centred worldview and in its techno-optimism rejects all things biological - ending up focusing on the human brain alone. It resembles a religion with its prophets and promises of everlasting life. It is often noncritical towards the power structures it imposes and embraces the technocapitalist system it has born out of (Berardi 2014). Transhumanist tale is however a powerful narrative that drives our popular imagination as can be seen in multiple science fiction TV-series and films produced in recent years and decades (Terminator, Black Mirror, West World etc.). And if we look around us: the human-machine hybrids are already here.

\subsection{Biology meets technology}

The early manifestations of these hybrid lifeforms can be seen in our culture as new technologies change us and alter our ways of perceiving. Our electrical devices are turning our perception inwards to a point when the devices themselves crawl under our skins. This change takes place in the time of technocapitalism, where these new tools are used for economic gains and work efficiency (Berardi 2014). For example, in Sweden a think tank organized microchip parties to insert electronic NFC implants into participating employees (Brooks 2017). 
If taken seriously, these developments raise a multitude of questions also for artistic practice. How could we imagine the sensory existence of a machine - and coexist with it? How will an intelligent machine perceive art? When looking back to the age of pre-Singularity, could the intelligent machine say: this is art, this was made for me?

\subsection{Previous artistic examples}

The Brains on Art collective is by no means the first one to engage in the similar line of thought in the arts. Performance artist Stelarc has since the 60's discussed the body as an obsolete category and merged his own body with different technologies. He grew a third ear in his arm and inserted a microphone into it, and in another performance controlled a robotic arm with his stomach muscles.

In 2016 The Digital Arts Biennial in Montréal was titled as "AUTOMATA: Art made by machines for machines" where the themes of artificial intelligence and transcending our physical boundaries were discussed through both visual and narrative means.

Two examples from recent years from Finland alone: 2017 a contemporary dance choreography "Robots Don't Dream" by Ismo-Pekka Heikinheimo and dancer Tanja Illukka portrayed a human-robot created to execute dance performances in a pool of black fluid, and a 2018 performance called "Constitutive Meeting of The AI Party" by The Center for Everything group, where an Al was thought by the participants in order to form a political movement led by the Al system created in the performance.

\section{THEORETICAL TOOLS}

But how to understand the machine? What are the theoretical tools we could use when talking about the machine experience or what could art mean for a machine? After laying down the scene (artistic practice, prophesies and new hybrid lifeforms), we must next consider the tools at hand to help us in negotiating an experience to a machine. In the scope of this project the Brains on Art collective has looked into posthumanist writings, different theories of art and artistic research methodologies.

\subsection{After human}

When imagining what might come after human and about non-human agencies, posthumanist thinking comes in play. This strand is critical towards the human-exceptionalism of traditional humanism (thus labelled often as critical posthumanism in contrast to transhumanist tradition). Posthumanist writers treat humans as co-evolving together with non-humans, sharing ecosystems and even genetic material with them. It criticises the disembodied and reasoncentred view of transhumanism and sees technology not as mere prosthesis to human but as integral to human identity. Thus, posthumanism offers more inclusive understanding of life (Nayar 2014).

Especially for highlighting the agency of a machine posthumanist theorizing seems fruitful, as it highlights the agency of other-than-human beings (Wolfe 2010). In contrast to transhumanism which is very much human-centred, the posthumanist line of thought makes us reconsider our own role in relation to other beings, and thus can help us recognize the agency of an animal, a plant, or the technological other: a machine (Braidotti 2013).

Although the Machine Spectator project was initially inspired by the transhumanist fantasies about artificial super intelligence looking at art, it has since moved towards a posthumanist understanding of coevolution with different non-humans around us. The exploration into machinic experiences has since been fuelled by the interest towards different ways the machines sense their surroundings and how the human realm of aesthetic experiences could be translated for these developing technologies.

\subsection{Demarcation of art}

For theorizing what art could mean for a machine, we must first consider what do we mean by art. Here I suggest the tools can be found from the art theories. I briefly present two theories of art that have shown promise in our artistic process of translating art and aesthetic experience for a machine, although it is important to remember that both of these theories have their limitations, and more thorough work would be needed in applying them for a machine.

\subsubsection{Art as Experience (what could be an aesthetic experience for a machine?)}

John Dewey (1859 - 1952) makes distinction between art object and art work, where the latter happens in relation with the viewer - as an experience. The aesthetic experience is enabled by aesthetic form of the art object. For Dewey, aesthetic experience is a reward of its own right, without utility function (Dewey 2005).

Dewey has been criticized for too limiting view on the spectrum of aesthetic experiences as he seems to exclude sudden sensations without temporal dimension. On the other hand, Dewey's definition seems to be too wide, as it seems to include phenomena that are not considered art (Carroll 2001). However, some aspects of Dewey's theory seem useful for future contemplation.

Dewey takes the human sensory connection with the world as the starting point for defining experience. For the purpose of translating aesthetic experience for a machine the starting point would then be to research into the sensory capabilities of the machine. 
In an example from Art as experience (2005) Dewey imagines what an experience would mean for a stone:

\begin{abstract}
A generalized illustration may be had if we imagine a stone, which is rolling down hill, to have an experience. The activity is surely sufficiently "practical". The stone starts from somewhere, and moves, as consistently as conditions permit, toward a place and state where it will be at rest toward an end. Let us add, by imagination, to these external facts, the ideas that it looks forward with desire to the final outcome; that it is interested in the things it meets on its way, conditions that accelerate and retard its movement with respect to their bearing on the end; that it acts and feels toward them according to the hindering or helping function it attributes to them; and that the final coming to rest is related to all that went before as the culmination of a continuous movement. Then the stone would have an experience, and one with esthetic quality. (Dewey 2005)
\end{abstract}

Although he presents this as an imaginary example, Dewey lays down the conditions needed for a nonliving being to have an experience.

\subsubsection{Institutional theory of art (how to demarcate art for a machine?)}

In the 1960s and 1970s George Dickie formulated institutional theory of art, that emphasized the significance of art institutions in defining what is art. According to Dickie, the artworks cannot be defined by their aesthetic functions. Instead Dickie, connecting the artwork to the social and cultural network and drawing from Arthur Danto's concept of 'the artworld', states in his book, Art and the Aesthetic: An institutional analysis (1974), that:

\begin{abstract}
A work of art in the classificatory sense is (1) an artefact (2) a set of the aspects of which has had conferred upon it the status of candidate for appreciation by some person or persons acting on behalf of a certain social institution (the artworld). (Dickie 1974)
\end{abstract}

Dickie's definition and especially the vagueness of the concept of artworld has since been challenged, but in our case Dickie's intention of shifting the attention to the context rather than the art object, which in case of e.g. Duchamp's Fountain can be physically indistinguishable from non-art objects (Todd 2007), proved to be helpful in our artistic endeavour as discussed further.

The translations of art theories to a computer can offer new insight on what the technological other could see as art. And by considering different art theories and their applications for a machine, we also shed light on our own understanding of art.

\subsection{Artistic research}

A third theoretical tool used in our project is the methodology of artistic research. Artistic research creates new knowledge through artistic practice. Rooted in practice, the artistic research can tap to knowledge produced through art making (Hannula et al. 2005).

By creative and systematic artistic process, Brains on Art collective is developing a suggestion to answer the research question about art and machine experience. The suggestion includes articles that open up the thinking process, and an artwork - a yet untitled Machine Spectator.

When trying to imagine an emergent being such as technological other with aesthetic experiences, artistic research can help us concentrate on the underlying meanings of new technologies on very concrete scale. By creating such a being as an art project, new knowledge and insight to the topic can be produced.

\section{NEGOTIATING THE EXPERIENCE}

At this point it is good to remember that aesthetic judgement calls are already been made by machines on a day-to-day basis. The following examples inform our artwork in how to translate the aesthetic judgement - the taste - to a computer.

The first patents for "computerized aesthetic judgment of images" was filed in 1999 by Microsoft (Toyama 2004). To give the reader a glimpse of what were seen to be the problems I quote the patent here:

\begin{abstract}
A shortcoming of current graphics applications for computers, however, is that they cannot judge the end result of a user's creation. Many graphics applications... provide wizards and templates to make the creation of images easier and make the end result more professional looking. However, because the user is still given considerable discretion in the designing of the images, even when using wizards and templates, the user may unknowingly create something that looks unprofessional, or even garish-looking. Besides asking family, friends and co-workers for their opinions-who themselves are likely to be nonprofessionals-the user has few options for determining how aesthetic his or her image is. (Toyama 2004)
\end{abstract}

The problem was actually the human user, who's aesthetic judgement was not to be trusted!

A more recent example of an aesthetic machine: Berlin-based start-up EyeEm is a photo sharing and stock image platform that uses machine learning systems to give photos aesthetic scores. The startup even hosted a photo contest where the shortlist was determined by Al, pre-trained to know the visual 
preferences of the human judges (Grigoris 2017). The Al called the "Aesthetic Image Recognition Technology" determines an aesthetic score for images (Shaji \& Rizk 2017). It is taught by human judges and learns what pleases their visual eye.

And of course, the social media platforms are making judgement calls based on our virtual profile's preferences all the time. Or consider the Spotify's suggested playlists. Netflix and Amazon already use their analytics to produce series according to the preferences of the viewers (Idato 2015).

The machines are already deeply involved in the aesthetic decision-making.

What is then an aesthetic machine?

As we know art and aesthetics are not the same thing. Three sub-questions arise:

(i) Recognition: what the machine considers as art versus non-art?

(ii) Evaluation, taste: what does the machine think is good art?

(iii) What could an aesthetic experience mean for a machine?

\section{ARTISTIC PROCESS}

Our Brains on Art collective set out to tackle these questions by making art for a machine. We started the project in October 2017 with discussions and meetings, where we shared the different ways of interpreting machine experience and the technological tools at hand to help us realize the task. The discussions ranged from introductions of different art theories to the inner workings of a machine learning system. We also delved into contemporary art and technological innovations in order to gain insight on the previous work done in the field, and inspiration for our own work.

We were considering an exhibition where humans could bring their own machine helpers, like Roomba's or Alexa's in. What would a poetry slam for Siri be like?

At one point I was suggesting that we could try to assign some states of the machine (such as the amount of processing using to complete a task) corresponding some human emotional states (such as distress), but at least for now we haven't moved forward with this idea.

\subsection{Architecture}

Finally, to answer the three questions about the machine recognizing, evaluating and even enjoying art, we decided to focus on one question at a time, starting with the problem of recognition.

The first and still unnamed art installation "Machine Spectator" is a learning program for image recognition that uses deep convolutional neural networks. These networks have been central to the advances in image recognition in recent years. The Inception architecture chosen has been shown to achieve very good performance at relatively low computational cost (Szegedy et al. 2016). The network is pre-trained with ImageNet database organized according to the WordNet hierarchy.

The program tries to recognize different patterns within the image data and group the images according to their proximity in 1500-dimentional space. The final outcomes would be tags like "dog", "human", or "car". Instead we interrupt the process in mid-flight in order to get more general groupings out of the network.

In this first attempt we are following the institutional art theory when selecting the dataset for the category of art. Most of the big art museums in the world have comprehensive online archives and some of them provide access through Application Programming Interfaces (API).

Our first dataset comes from the Finnish National Gallery which includes art collections from three museums: Ateneum and Sinebrychoff archives for classical and pre-1960's art, and Kiasma collection for contemporary art. All together over 34000 images of different art from paintings, to photographs and installation shots. Thus, the first Machine Spectator is thought by human made-art. Here we are suggesting the use of art theories (such as the institutional art theory) for the machine.

In the visualization we currently use the t-SNE dimensionality reduction technique, that can show the proximity of images in 2D or 3D space (van der Maaten \& Hinton 2008).

\subsection{Presentation}

Our idea is to present the spectator as an interactive installation, where human visitor can show the machine new images and it will reorganize the image cloud in new ways according to the changed proximity of the artworks.

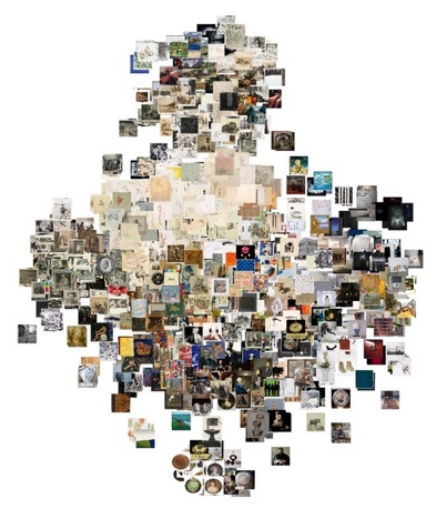

Figure 1: First 1000 images from the Finnish National Gallery grouped by the Machine Spectator with $t$-SNE. 
We have considered different presentation locations, such as Helsinki University's Science Corner and Aalto University's bioart laboratory Biofilia. Currently we are intrigued by the possibility to create a movable Machine Spectator, that could visit different exhibitions with us and give feedback from the art it sees.

\subsection{Challenges}

We have encountered some interesting problems with our first Machine Spectator.

The current version cannot independently distinguish art from non-art. In order to understand art as a separate category, the machine would also need a database of "not-art". As we have knowingly limited ourselves in the use of images alone (at least for the time being), this seems like an impossible task to achieve. Art is not defined by any property of the image, but rather it's connection to other art works, and the context it was made and encountered in. Here the institutional art theory becomes useful: we can state, that only the images from certain museum or gallery databases constitute as art works. Here the recognition is outsourced to art institutions.

Another problem we encountered is that for a machine quantity is more important than quality when finding patterns from the data. However, some artists are over-represented in the database. For example, Finnish artist Kalervo Palsa has a wideranging corpus of more than 3000 mostly erotic and violent artworks inside the database. This can skew the network, which in a way could result in interesting tendencies. In future we could use for example a similar aesthetic rating system to the EyeEm start-up discussed earlier in developing the Machine Spectator an aesthetic sense of its own.

The networks we are using are already pre-trained. For example, the ImageNet database is composed exclusively of photographs. This might have an impact when working with dataset including drawings and paintings. The technologies we use assume a human user. Can artificial human-made machine escape its human origins? Can one untrain a machine learning network?

\subsection{Futures}

When moving forward we have set ourselves two more installation goals to highlight different aspects of the aesthetic experience of the machine.

The second installation is exploring the second subquestion: the possibilities of evaluation and taste preferences. Whereas the first Machine Spectator is thought within the context of human made art, the second tries to expand to the realm of machine made art. We are interested in giving the machine some creative freedom. We propose a two-part installation, including an art producing machine and a machine evaluator. Here the producer part creates images of its own, trying to fool the evaluator part in believing they are part of the art database.

In machine learning literature, this technique for generating images is referred to as a Generative Adversarial Network (Goodfellow et al. 2014). It is used to generate novel samples that would be indistinguishable from those in the evaluators database. But instead of moving in one direction of increasing similarity, what if we could have the creative process of the machine feedback and guide the goals of the activity?

After a certain time, we plan to take the most convincing images the creative part has created (although still far away from the normally wanted outcome) and add them to the pool of the evaluator's database. As the time goes by, we hope to achieve a new form of machine-produced art for a machine. What happens if we give the machine free hands to re-determine the database on its own terms? Will we end up with a grey square, or something more interesting? What kind of taste preferences are produced?

Thirdly we'll try to create a sense of aesthetic for a sand drawing robot in order to explore the third subquestion: the translation of the aesthetic experience. In the interactive installation the human visitor can make a disturbance in the sand drawing. The drawer then changes its parameters in order to try to assimilate the newly made disturbance into the sand drawing in an aesthetically pleasing way. In this version we could use John Dewey's theory of art as experience as a starting point to negotiate experience for a non-living machine. Another approach could be to create an aesthetic scoring system similar to the previously mentioned EyeEm aesthetic rating dataset as a base for building the machine an aesthetic sense of its own.

\section{CONCLUSIONS}

In conclusion, the Machine Spectator project has highlighted certain ontological aspects of the technological experience and art.

Art as a category is not something that could be derived from image alone. However, art theories can be used in negotiating aesthetic experience to a machine. Further research is needed in order to adapt different art theories for machine learning systems.

Weights in a large database of human made art can skew Machine Spectator's opinions of how to group the artworks.

The art project to translate aesthetic experience to a machine can shed light on the machine experience. Artistic manifestations can help us understand new 
phenomena, like artificial intelligence and machine learning systems, and imagine them in different light - as co-sensing technological beings.

The different artistic and academic parts of the project are forming a suggestion of how the aesthetic experience and art could be negotiated for a machine.

\section{REFERENCES}

Berardi, F. (2014) And. Phenomenology of the end. Aalto ARTS Books, Helsinki.

Bostrom, N. (2005) A History of Transhumanist Thought. Journal of Evolution and Technology, 14(1), pp. 1-25.

Braidotti, R. (2013) The Posthuman. Polity Press, Cambridge.

Brooks, J. (2017) Swedish workers implanted with microchips to replace cash cards and ID passes. Independent.

https://www.independent.co.uk/news/world/europe/ sweden-workers-microchip-implant-cash-card-idpass-replace-employee-hand-epicenter-rice-grainsize-a7670551.html (retrieved 11 June 2018).

Carroll, N. (2001) Beyond Aesthetics: Philosophical Essays. Cambridge University Press, Cambridge.

Clark, A. (2003) Natural-born Cyborgs: Minds Technologies and the Future of Human Intelligence. Oxford University Press, New York.

Dewey, J. (2005) Art as experience. Penguin Books, New York.

Dickie, G. (1974) Art and the Aesthetic: An institutional analysis. Cornell University Press, London

Goodfellow, I., Pouget-Abadie, J., Mirza, M., Xu, B., Warde-Farley, D., Ozair, S., Courville, A., and Bengio, J. (2014) Generative Adversarial Networks. eprint arXiv:1406.2661, 06/2014.

Grigoris, H. (2017) Al helps judges select top images for EyeEm contest from 590,000 entries. Digital Trends.

https://www.digitaltrends.com/photography/eyeemphotography-awards-2017-finalists/ (retrieved 11 June 2018).

Hannula, M., Suoranta, J., Vadén, T., Griffiths, G., and Kölhi, K. (2005) Artistic research: theories, methods and practices. Academy of Fine Arts, Helsinki.

Haraway, D. (1991) Simians, Cyborgs, and Women: The Reinvention of Nature. Routledge, New York.

Idato, M. (2015) Netflix's algorithm matches content to eyeballs and is rewriting the TV rulebook. The
Sydney Morning Herald.

https://www.smh.com.au/entertainment/tv-andradio/netflixs-algorithm-matches-content-toeyeballs-and-is-rewriting-the-tv-rulebook20150731-gintcf.html (retrieved 11 June 2018).

Kurzweil, R. (2005) The Singularity Is Near. Viking Penguin, New York.

McLuhan, M., and Fiore, Q. (1967) The medium is the massage. Bantam, New York.

Nayar, P. K. (2014) Posthumanism. Polity Press, Cambridge.

Roden, D. (2015) Posthuman Life: Philosophy at the Edge of the Human. Routledge, New York

Savransky, M., Wilkie, A., and Rosengarten, M. (2017): The lure of possible futures: on speculative research. In Wilkie, A., Savransky, M., and Rosengarten, M. (eds.). Speculative Research: The Lure of Possible Futures, Routledge, New York.

Shaji, A., Rizk, R. (2017) Systems, methods, and computer program products for searching and sorting images by aesthetic quality. United States Patent, US 9659384B2.

Szegedy, C., loffe, S., Vanhoucke, V., and Alemi, A. (2016). Inception-v4, Inception-ResNet and the Impact of Residual Connections on Learning. eprint arXiv:1602.07261, 02/2016.

Taylor, G D (2014) When the Machine Made Art: the troubled history of computer art. Bloomsbury, New York.

Todd, C. S. (2007) George Dickie (1926-). In Costello, V., and Vickery, J. (eds.). Art: key contemporary thinkers, Berg, New York.

Toyama, K (2004) Computerized aesthetic judgment of images. United States Patent, US 6816847B1.

Van der Maaten, L., and Hinton. G. (2008) Visualizing Data using t-SNE. Journal of Machine Learning Research, 1 (2008), pp. 1-48

Vinge, V. (1993) The Coming Technological Singularity. Whole Earth Review Winter issue.

Wolfe, C (2010) What is posthumanism? University of Minnesota Press, Minneapolis. 